\title{
Results of an International Survey of Practice Patterns for Establishing Prognosis in Neck Pain: The ICON Project
}

\author{
David M. Walton ${ }^{*}, 1$, Joy C. MacDermid ${ }^{2}$, P. Lina Santaguida ${ }^{3}$, Anita Gross ${ }^{4}$, Lisa Carlesso ${ }^{3}$ and \\ $\mathrm{ICON}^{5}$
}

\author{
${ }^{1}$ School of Physical Therapy, Western University, London Ontario, Canada \\ ${ }^{2}$ School of Rehabilitation Sciences, McMaster University, Hamilton Ontario, and Clinical Research Lab, Hand and \\ Upper Limb Centre, St. Joseph's Health Centre, London Ontario, Canada \\ ${ }^{3}$ Department of Clinical Epidemiology and Biostatistics, McMaster University, Hamilton Ontario, Canada \\ ${ }^{4}$ School of Rehabilitation Sciences, McMaster University, Hamilton, Canada \\ ${ }^{5}$ International Collaboration on Neck (ICON)
}

\begin{abstract}
Results of an international survey of health care providers for neck pain are reported. The survey specifically collected self-reported practice patterns for establishing a prognosis in neck pain. Over 440 responses from 27 countries were collected. Descriptive results indicate that respondents assigned large prognostic impact to factors including mechanism of injury and psychological or behavioral constructs. Range of motion, age and sex were routinely collected despite relatively moderate impact on prognosis. A comparison between chiropractic and manual/physical therapy groups showed differences in practice patterns that were unlikely to affect prognostic accuracy. The results suggest a gap exists between current best-evidence and actual practice when the goal is to establish a prognosis in neck pain.
\end{abstract}

Keywords: Pain, prognosis, outcomes, survey, neck.

\section{INTRODUCTION}

Establishing a prognosis for outcome of a condition should be an important part of the assessment of clinical syndromes. A well-established prognosis provides a basis for clinical decision making; those with a favorable prognosis are usually appropriate for standard clinical treatment pathways, while those with an unfavorable prognosis may require deviation from standard pathways in an effort to mitigate the risk of undesirable outcomes. Prognosis is also valuable for establishing patient expectations for recovery and is a common component of communication with insurers or other third party payors. From a research standpoint, the identification of important prognostic factors could impact the design of clinical trials; in some cases, only those with a favorable prognosis are desired, such as in the creation and evaluation of standard clinical treatment pathways. In other cases, such as the evaluation of novel interventions, only those with an unfavorable prognosis may be desired to improve assay sensitivity [1]. These considerations have been detailed at length in a recent series of publications [24].

While prognosis is routinely established in some conditions, such as cancer [5] or following orthopedic hip

\footnotetext{
*Address correspondence to this author at the Rm. EC1443, School of Physical Therapy, Western University, 1201 Western Rd., London, ON N6H 1A1, Canada; Tel: 519-661-2111, Ext. 80145; Fax: 519-661-3866;

E-mail: dwalton5@uwo.ca
}

and knee surgery [6], it is less frequently established for the common condition of neck pain. This is despite evidence that neck pain represents one of the most costly conditions in industrialized countries, especially when both direct (medical and rehabilitation) and indirect (lost productivity) costs are considered [7-9]. It could be argued that one of the primary reasons that prognosis in neck pain is not routinely established is owing to the lack of consensus on the most important prognostic factors to evaluate. An emerging consensus amongst systematic reviews evaluating prognostic factors in neck pain would suggest that higher initial pain intensity and self-reported disability scores are associated with an unfavorable outcome, and that parameters of the accident in traumatic neck pain do not tend to affect outcome [10-15]. Little consistency is found beyond these factors.

The International Collaboration on Neck Pain (ICON) project is a collaborative project of internationallyrecognized experts in the field of neck pain. The goal of the ICON project is to establish clear, actionable messages in the pillars of diagnosis/classification, prognosis, intervention and outcomes measurement. Recognizing the existing limitations in the published literature on neck pain, especially in the area of prognosis, one of the tools the ICON project has implemented to inform the development of these guidelines is an international survey of clinical practice patterns. Understanding existing practice patterns provides information that cannot be gleaned from peer-reviewed empirical evidence and can indicate gaps between prevailing beliefs and existing evidence. Presumably, clinicians practice in a way that makes sense within their context, influenced by 
resources, cultural beliefs, interpretation of evidence, and concordance with their own theoretical understanding of the causes and mechanisms of neck pain. These factors are rarely captured by researchers. Surveys of practice patterns are useful not only for identifying discordance between practice and evidence, but also for identifying research priorities based on practice patterns.

This manuscript describes the results of an international cross-disciplinary on-line survey of practice patterns with specific focus on establishing prognosis in neck pain as part of the ICON project. The survey results are then considered in light of the existing state of published evidence in the area of neck pain management.

\section{METHODS}

A cross-sectional survey to determine the practice patterns of clinicians who provide care to patients with neck pain was conducted from October 2011 to May 2012. The survey was approved by the relevant University Research Ethics Board.

\section{Survey Development and Validation}

This survey was developed as a component within a larger survey strategy designed to acquire information in four principle content areas (examination/diagnostic procedures, prognostic indicators, treatments, and outcome measures). These four areas were developed and administered separately; only the prognosis component is described here. Demographic and caseload information was also collected to facilitate interpretation.

The survey items were developed from published empirical evidence or expert opinions on current clinical practice. The lead authors, each with clinical and research expertise in the field of neck pain, performed additional item generation to augment areas that were perceived to be lacking from the literature-driven generation. Items were designed to be appropriate for different clinical disciplines including the following groups that commonly treat people with neck pain: physicians, psychologists, physiotherapists, massage therapists, chiropractors, and other rehabilitative professions.

The items were reviewed by an expert panel (ICON working group) who made suggestions based on both content and wording. An arms-length expert clinical group $(n=38)$ that included representatives from all the professions in our target audience were used for pilot testing. The pilot evaluation focused on the usability of the formatting, and the routing logic when items were not relevant to a particular respondent. These experts also reviewed the survey for accuracy, clarity, completeness and burden. Editing for clarity was performed after the pilot testing. This resulted in changes to items for clarity, a very few number of additions, and adjustment to the overall response format. Due to concerns about respondent burden, we selected a format that allowed collection of both frequency of use and importance simultaneously. The finalized version of the survey was mounted using LimeSurvey ${ }^{1}$, an open-source secure software platform for web-based survey administration.

The items spanned the domains of biological, psychological and social/environmental prognostic factors.

${ }^{1}$ LimeSurvey software, Survey Service \& Consulting, Hamburg, Germany.
An "Other" option was provided in a limited number of circumstances where we anticipated there might be specific responses that had not been adequately captured. For each item, respondents were asked whether they routinely (at least $75 \%$ of the time) collected information about each factor for the express purpose of establishing a prognosis (yes/no) and how large of an impact each factor had on prognosis for their patients with neck pain (no effect, small, moderate, large or critical effect). Demographic characteristics of the respondents and the description of their clinical context and caseload information were collected at the end of the survey.

\section{Sampling Frame}

The intended sampling frame was clinicians that treat neck pain including multiple disciplines and countries to provide a broad perspective of opinions. Health practitioners who self-declared a significant component of patients with neck pain in their caseload were included. 'Snowball' recruitment strategies were employed, where experts were identified within each of the professions who then assisted by sending out the survey link to their professional colleagues. Survey invitations were distributed via e-mail blast to members, and/or electronic postings (e.g., enewsletter, website, Facebook ${ }^{\circledR}$ or Twitter $\left.\AA\right)$, by professional groups for chiropractors (Danish Chiropractors' Association; European Academy of Chiropractic; Netherlands Chiropractic Association; New Zealand Chiropractors' Association; Ontario Chiropractic Association); manual therapists (Canadian Academy of Manipulative Physical Therapists, Dutch Association for Manual Therapy; Finnish Association for Orthopedic Manual Therapy; German Manual Therapy Journal; Internatonal Federation of Orthopaedic Manipulative Physical Therapists); massage therapists (Massage Therapists' Association of British Columbia); physicians (North American Spine Society; University of British Columbia Department of Family Medicine); physiotherapists (American Physical Therapy Association - Orthopedic Section; Canadian Physiotherapy Association - Pain Sciences Division \& Orthopedic Division; Hong Kong Physiotherapy Association; Musculoskeletal Physiotherapy Australia); and other health care professionals (Osteopathic Society of New Zealand). We could not calculate response rates to our survey invitations as we were unable to determine how many people received our requests for participation.

The prognosis survey took approximately 15-20 minutes to complete. Public registration was required to participate in the survey and individuals who signed up to receive the survey link were considered "registrants". Registrants who completed at least one section of the survey were included in the analysis. Invitations were sent on multiple occasions to the target groups.

\section{ANALYSIS}

Data quality was assessed by randomly sampling $10 \%$ of the dataset to check for errors. Discrepant entries were resolved to less than $1 \%$ through this process. Descriptive statistics were used to summarize participants and their responses to each question. Owing to the predominant representation of manual/physical therapists (MT/PT combined) and chiropractors in our pool of registrants, 
statistical tests of difference between disciplines were conducted for only these 2 subgroups. Z-tests with Bonferroni correction $(0.05 / 5$ comparisons per item, $\alpha=$ 0.01 ) were used to identify differences in response frequencies between the two professional groups.

\section{RESULTS}

The Prognosis survey had 588 registrants, with 492 of those completing at least one section of the survey (440 full responses, 52 partial). Respondent numbers decreased with consecutive subsections, with the first (physical factors) section having the highest number of complete responses at 463 , to 444 complete responses on the 'social \& environmental factors' section, and 440 through the demographics section.

Table 1 presents the demographic information of the respondents. Responses were collected from 27 different countries, with Canada (44.5\%) and the United States (19.4\%) most commonly represented. Chiropractors $(39.6 \%)$ and Physical Therapists $(33.3 \%)$ were the most common health professions represented, with at least 1 response from 9 other professions. The majority $(62.7 \%)$ of respondents worked in a private clinic, saw a primarily outpatient caseload $(75.5 \%)$, and were reimbursed through a private fee-for-service model $(56.5 \%)$. The majority of respondents indicated that clients with neck pain comprised between a quarter and half of their caseload. An additional 23.2\% indicated that neck pain accounted for more than half of their caseload. We had good representation of both males and females, an acceptable range of clinical experience, and broad representation of academic credentials.

Table 1. Characteristics of the Pool of Respondents

\begin{tabular}{|l|l|}
\hline Country & $\mathbf{N}=\mathbf{4 4 3}$ \\
\hline \hline Australia & $13(2.9 \%)$ \\
Belgium & $10(2.3 \%)$ \\
Brazil & $4(0.9 \%)$ \\
Canada & $197(44.5 \%)$ \\
Denmark & $51(11.5 \%)$ \\
Egypt & $2(0.5 \%)$ \\
Finland & $4(0.9 \%)$ \\
France & $1(0.2 \%)$ \\
Germany & $12(2.7 \%)$ \\
Greece & $1(0.2 \%)$ \\
Hong Kong & $2(0.5 \%)$ \\
India & $2(0.5 \%)$ \\
Iran & $1(0.2 \%)$ \\
Ireland & $9(2.0 \%)$ \\
Italy & $1(0.2 \%)$ \\
Japan & $1(0.2 \%)$ \\
The Netherlands & $3(0.7 \%)$ \\
New Zealand & $20(4.5 \%)$ \\
Norway & $2(0.5 \%)$ \\
Portugal & $1(0.2 \%)$ \\
South Africa & $3(0.7 \%)$ \\
Spain & $3(0.7 \%)$ \\
Sweden & $3(0.7 \%)$ \\
Switzerland & $2(0.5 \%)$ \\
Turkey & $1(0.2 \%)$ \\
United Kingdom & $8(1.8 \%)$ \\
United States & $86(19.4 \%)$ \\
\hline
\end{tabular}

(Table 1) contd.....

\begin{tabular}{|c|c|}
\hline Profession & $\mathrm{N}=\mathbf{4 8 0}$ \\
\hline $\begin{array}{l}\text { Chiropractor } \\
\text { CAM } \\
\text { General Physician } \\
\text { Manual therapist } \\
\text { Massage therapist } \\
\text { Nurse } \\
\text { Other Specialist Physician } \\
\text { Other Health Care Provider } \\
\text { Physical therapist } \\
\text { Physiatrist } \\
\text { Psychologist }\end{array}$ & $\begin{array}{l}190(39.6 \%) \\
6(1.3 \%) \\
2(0.4 \%) \\
51(10.6 \%) \\
31(6.5 \%) \\
2(0.4 \%) \\
27(5.6 \%) \\
34(6.9 \%) \\
160(33.3 \%) \\
10(2.1 \%) \\
1(0.2 \%)\end{array}$ \\
\hline Facility & $N=549 *$ \\
\hline $\begin{array}{l}\text { General hospital } \\
\text { Teaching hospital } \\
\text { Community care/Home care } \\
\text { Private clinic } \\
\text { Worker's compensation evaluation centre } \\
\text { Inpatient rehabilitation centre } \\
\text { Outpatient rehabilitation centre } \\
\text { Short-term extended care facility } \\
\text { Permanent residential facility } \\
\text { Industry } \\
\text { Private consultant (not clinic based) } \\
\text { Other }\end{array}$ & $\begin{array}{l}38(6.9 \%) \\
44(8.0 \%) \\
9(1.6 \%) \\
344(62.7 \%) \\
8(1.5 \%) \\
7(1.3 \%) \\
36(6.6 \%) \\
1(0.2 \%) \\
2(0.4 \%) \\
2(0.4 \%) \\
31(5.6 \%) \\
27(4.9 \%)\end{array}$ \\
\hline Caseload & $\mathrm{N}=\mathbf{4 4 0}$ \\
\hline $\begin{array}{l}\text { Caseload } \\
\text { Outpatient only } \\
\text { Inpatient only } \\
\text { Mixed }\end{array}$ & $\begin{array}{l}332(75.5 \%) \\
38(8.6 \%) \\
70(15.9 \%)\end{array}$ \\
\hline Proportion of Patients with Neck Pain & $\mathrm{N}=440$ \\
\hline $\begin{array}{l}<5 \% \\
6-25 \% \\
26-50 \% \\
>50 \%\end{array}$ & $\begin{array}{l}8(1.8 \%) \\
119(27.0 \%) \\
211(48.0 \%) \\
102(23.2 \%)\end{array}$ \\
\hline Sex & $\mathrm{N}=\mathbf{4 4 0}$ \\
\hline $\begin{array}{l}\text { Male } \\
\text { Female }\end{array}$ & $\begin{array}{l}252(57.3 \%) \\
188(42.7 \%)\end{array}$ \\
\hline Health Care System & $\mathrm{N}=817 *$ \\
\hline $\begin{array}{l}\text { Private insurance } \\
\text { Public health insurance } \\
\text { Worker's compensation }\end{array}$ & $\begin{array}{l}373(45.7 \%) \\
218(26.7 \%) \\
226(27.7 \%)\end{array}$ \\
\hline Salary System & $\mathrm{N}=529 *$ \\
\hline $\begin{array}{l}\text { Fixed salary } \\
\text { Fee for service (public) } \\
\text { Fee for service (private) }\end{array}$ & $\begin{array}{l}131(24.8 \%) \\
99(18.7 \%) \\
299(56.5 \%)\end{array}$ \\
\hline Highest Degree Obtained & $N=440$ \\
\hline $\begin{array}{l}\text { Diploma } \\
\text { Bachelor's } \\
\text { Master's } \\
\text { MD } \\
\text { Doctorate/PhD } \\
\text { Other }\end{array}$ & $\begin{array}{l}33(7.5 \%) \\
81(18.4 \%) \\
110(25.0 \%) \\
49(11.1 \%) \\
97(22.0 \%) \\
70(15.9 \%)\end{array}$ \\
\hline Years in Practice (Mean (Median, Range)) & $16.0(15.0,0$ to 50$)$ \\
\hline
\end{tabular}


Table 2. Complete Description of Results from the Prognosis Survey

\begin{tabular}{|c|c|c|c|c|c|c|c|}
\hline Physical Factors & $\mathbf{N}$ & Percent Collect & \multicolumn{5}{|c|}{ Size of Impact } \\
\hline Type of pain (neuropathic $v s$ nociceptive) & 463 & $92.7 \%$ & $20.5 \%$ & $49.9 \%$ & $24.6 \%$ & $4.8 \%$ & $0.2 \%$ \\
\hline Neck weakness & 463 & $80.8 \%^{\mathrm{b}}$ & $11.9 \%$ & $33.3 \%$ & $38.7 \%$ & $15.1 \%$ & $1.1 \%$ \\
\hline Sensory/dermatomal abnormalities & 462 & $93.1 \%$ & $20.1 \%$ & $35.7 \%$ & $33.1 \%$ & $10.0 \%$ & $1.1 \%$ \\
\hline Cervical ligament viability (manual) & 462 & $65.2 \%$ & $27.1 \%^{\mathrm{b}}$ & $26.4 \%$ & $28.4 \%$ & $12.8 \%^{\mathrm{a}}$ & $5.0 \%$ \\
\hline Diagnostic imaging & 462 & $60.0 \%$ & $13.9 \%^{\mathrm{a}}$ & $22.1 \%^{\mathrm{a}}$ & $38.1 \%$ & $24.2 \%^{\mathrm{b}}$ & $1.7 \%$ \\
\hline EMG/NCV & 462 & $24.5 \%^{\mathrm{b}}$ & $8.0 \%$ & $26.0 \%$ & $38.3 \%$ & $20.3 \%$ & $7.4 \%$ \\
\hline \multirow{2}{*}{ Psychological/Behavioral Factors } & \multirow[b]{2}{*}{$\mathbf{N}$} & \multirow{2}{*}{ Percent Collect } & \multicolumn{5}{|c|}{ Size of Impact } \\
\hline & & & Critical & Large & Moderate & Small & None \\
\hline Recovery expectations & 454 & $83.9 \%^{\mathrm{b}}$ & $30.6 \%$ & $52.9 \%$ & $14.5 \%$ & $1.8 \%$ & $0.2 \%$ \\
\hline Likelihood of compliance & 454 & $86.6 \%$ & $30.6 \%$ & $51.5 \%$ & $17.0 \%$ & $0.9 \%$ & $0 \%$ \\
\hline Psychological disorder (ie. anxiety, depression) & 454 & $73.3 \%$ & $23.1 \%$ & $50.0 \%$ & $23.8 \%$ & $2.6 \%$ & $0.4 \%$ \\
\hline Cognitive/behavioral factors (observed) & 454 & $66.5 \%^{\mathrm{b}}$ & $35.7 \%$ & $44.3 \%$ & $17.2 \%$ & $2.4 \%$ & $0.4 \%$ \\
\hline Cognitive disturbances (ie. memory, concentration) & 454 & $56.6 \%$ & $10.6 \%$ & $36.8 \%$ & $37.2 \%$ & $13.9 \%$ & $1.5 \%$ \\
\hline Cognitive tests & 454 & $6.6 \%$ & $2.2 \%^{\mathrm{a}}$ & $18.9 \%$ & $41.9 \%$ & $26.0 \%$ & $11.0 \%$ \\
\hline Symptoms \& Interference Factors & $\mathbf{N}$ & Percent Collect & \multicolumn{5}{|c|}{ Size of Impact } \\
\hline Disturbed sleep & 446 & $92.2 \%$ & $9.6 \%$ & $37.2 \%$ & $39.5 \%$ & $12.6 \%$ & $1.3 \%$ \\
\hline Pre-existing neck pain & 446 & $98.2 \%$ & $14.1 \%$ & $46.9 \%$ & $32.3 \%$ & $6.7 \%$ & $0.2 \%$ \\
\hline Prior neck trauma & 446 & $98.9 \%$ & $23.3 \%$ & $43.3 \%$ & $28.0 \%$ & $5.4 \%$ & $0.2 \%$ \\
\hline Type of onset (gradual $v s$ traumatic) & 446 & $98.9 \%$ & $18.6 \%$ & $42.4 \%$ & $28.9 \%$ & $9.6 \%$ & $0.7 \%$ \\
\hline Thoracic or shoulder pain & 446 & $98.7 \%$ & $8.1 \%$ & $29.8 \%$ & $44.8 \%$ & $14.8 \%$ & $2.7 \%^{\mathrm{a}}$ \\
\hline Pain intensity & 446 & $93.3 \%^{\mathrm{b}}$ & $9.4 \%$ & $33.9 \%$ & $44.8 \%$ & $11.7 \%$ & $0.2 \%$ \\
\hline Symptom location & 446 & $88.3 \%^{\mathrm{b}}$ & $9.4 \%$ & $30.3 \%$ & $39.0 \%$ & $17.9 \%$ & $3.4 \%$ \\
\hline Symptom duration & 446 & $98.9 \%$ & $14.6 \%$ & $53.4 \%$ & $30.3 \%$ & $1.8 \%$ & $0 \%$ \\
\hline Intake disability scales & 429 & $50.7 \%^{\mathrm{b}}$ & $7.0 \%$ & $30.0 \%$ & $46.4 \%$ & $13.9 \%$ & $2.7 \%$ \\
\hline \multirow{2}{*}{ Social \& Environmental factors } & \multirow{2}{*}{$\mathbf{N}$} & \multirow{2}{*}{ Percent Collect } & \multicolumn{5}{|c|}{ Size of Impact } \\
\hline & & & Critical & Large & Moderate & Small & None \\
\hline Lawyer involvement & 444 & $65.3 \%$ & $21.8 \%$ & $41.4 \%$ & $23.4 \%$ & $11.0 \%$ & $2.3 \%$ \\
\hline Insured compensation & 444 & $72.5 \%$ & $19.4 \%$ & $43.5 \%$ & $24.5 \%$ & $11.0 \%$ & $1.6 \%$ \\
\hline Psychosocial aspects of job (ie. satisfaction) & 444 & $60.6 \%$ & $21.2 \%$ & $45.9 \%$ & $27.7 \%$ & $4.3 \%$ & $0.9 \%$ \\
\hline Availability of alternative job duties & 444 & $75.5 \%$ & $8.3 \%$ & $43.2 \%$ & $38.7 \%$ & $8.3 \%$ & $1.4 \%$ \\
\hline Employment status & 444 & $89.9 \%$ & $10.6 \%$ & $38.1 \%$ & $38.7 \%$ & $11.0 \%$ & $1.6 \%$ \\
\hline
\end{tabular}




\begin{tabular}{|c|c|c|c|c|c|c|c|}
\hline \multirow{2}{*}{ Social \& Environmental factors } & \multirow{2}{*}{$\mathbf{N}$} & \multirow{2}{*}{ Percent Collect } & \multicolumn{5}{|c|}{ Size of Impact } \\
\hline & & & Critical & Large & Moderate & Small & None \\
\hline Ability to attend treatment & 444 & $79.5 \%$ & $21.6 \%$ & $43.9 \%$ & $26.6 \%$ & $7.9 \%$ & $0 \%$ \\
\hline Education level & 444 & $54.7 \%$ & $6.3 \%$ & $26.1 \%$ & $39.9 \%$ & $23.4 \%$ & $4.3 \%$ \\
\hline Age & 444 & $96.4 \%$ & $5.4 \%^{\mathrm{a}}$ & $26.1 \%$ & $39.6 \%$ & $23.6 \%$ & $5.2 \%$ \\
\hline Gender & 444 & $95.7 \%$ & $2.0 \%$ & $9.9 \%$ & $29.7 \%$ & $37.8 \%$ & $20.5 \%$ \\
\hline Race/ethnicity & 444 & $65.8 \%$ & $0.7 \%$ & $7.2 \%$ & $20.7 \%$ & $40.8 \%$ & $30.6 \%$ \\
\hline Literacy & 444 & $54.5 \%$ & $2.3 \%$ & $16.9 \%$ & $38.5 \%$ & $33.8 \%$ & $8.6 \%$ \\
\hline
\end{tabular}

${ }^{a}$ Denotes a significant difference in proportions, where chiropractors were more likely to endorse that category than physical therapists

${ }^{\mathrm{b}}$ Denotes a significant difference in proportions, where physical therapists were more likely to endorse that category than chiropractors

Table 2 presents the response frequencies from the 'routinely collected' and 'size of impact' survey questions. Physical factors and symptom/interference-related factors were collected most routinely (at least $75 \%$ of the time), with 7 of 11 physical factors and 9 of 11 symptom/interferencerelated factors routinely collected by at least $90 \%$ of respondents. The presence of radiating symptoms as a prognostic factor was collected by almost all (99\%) respondents, as were history of prior neck trauma, mechanism of onset, and symptom duration. None of the 6 psychological/behavioral factors and only 3 of 15 social/environmental factors were routinely collected by at least $90 \%$ of respondents for the purpose of establishing prognosis.

The cognitive or behavioral factors that were most highly endorsed by respondents were a preference for passive coping strategies, fear-avoidance, or catastrophic cognitions. These were endorsed as having a critical impact on prognosis by $36 \%$ of respondents, and were routinely collected by $67 \%$ of the respondents. This was followed closely by likelihood of compliance with treatment recommendations (31\% of respondents) and recovery expectations (31\% of respondents) as factors perceived to have a critical impact on establishing prognosis.

As a general summary, Table $\mathbf{3}$ presents those factors that were rated as having a large or critical impact on prognosis by at least $50 \%$ of all respondents. Recovery expectations and likelihood of compliance with treatment recommendations were most frequently given these ratings. Of note, gender (58\%) and race/ethnicity (71\%) were rated as having no or mild impact by the majority of respondents, despite gender routinely being collected for the purposes of establishing a prognosis by over $90 \%$ of respondents.

Table $\mathbf{2}$ also indicates those factors for which there was a significant difference in frequency of collection or size of perceived impact between the combined MT/PT group and the chiropractor group. Compared to the chiropractor group $(\mathrm{N}=190)$, more respondents in the MT/PT group $(\mathrm{N}=211)$ reported routinely evaluating neck weakness ( $88 \%$ vs $80 \%)$,
Table 3. Factors that at Least $50 \%$ of Respondents Rated as Having a Large or Critical Impact on their Determination of Prognosis in Neck pain. Order is Descending

\begin{tabular}{|l|l|}
\hline \multicolumn{1}{|c|}{ Factor } & Percent \\
\hline \hline Recovery expectations & $83.5 \%$ \\
\hline Likelihood of compliance & $82.1 \%$ \\
\hline Cognitive/behavioral factors (observed) & $80.0 \%$ \\
\hline Psychological disorder (ie. anxiety, depression) & $73.1 \%$ \\
\hline UE weakness* & $72.3 \%$ \\
\hline Type of pain* & $70.4 \%$ \\
\hline Accident factors* & $69.9 \%$ \\
\hline Radiating symptoms* & $69.5 \%$ \\
\hline Symptom duration* & $68.0 \%$ \\
\hline Prior neck trauma* & $66.6 \%$ \\
\hline Psychosocial aspects of job (ie. satisfaction) & $67.1 \%$ \\
\hline Ability to attend treatment & $65.5 \%$ \\
\hline Lawyer involvement & $63.2 \%$ \\
\hline Insured compensation & $62.9 \%$ \\
\hline Physical demands of the job & $61.3 \%$ \\
\hline Type of onset (gradual $\boldsymbol{v s}$ traumatic)* & $61.0 \%$ \\
\hline Pre-existing neck pain* & $61.0 \%$ \\
\hline Previous experiences with injury and recovery & $60.6 \%$ \\
\hline Sensory/dermatomal abnormalities* & $55.8 \%$ \\
\hline Attitude towards health care providers & $57.4 \%$ \\
\hline Cervical ligament viability & $53.5 \%$ \\
\hline Availability of alternative job duties & $51.5 \%$ \\
\hline & \\
\hline
\end{tabular}

Starred $(*)$ items represent those factors that are also routinely collected by at least $90 \%$ of respondents. 
EMG or nerve conduction tests (27\% vs 16\%), recovery expectations (89\% vs 80\%), cognitive/behavioral factors (76\% vs 64\%), pain intensity (98\% vs 87\%), symptom location (94\% vs 84\%) and baseline disability scale at intake $(62 \% v s 46 \%)$ for the purpose of establishing prognosis (all $\mathrm{p}$ $<0.01)$. In terms of size of perceived effect, the chiropractor group more frequently assigned a critical impact on prognosis to accident factors (33\% vs 22\%), diagnostic imaging (16\% vs $7 \%$ ), active range of motion (14\% vs $8 \%$ ), cognitive tests ( $3 \%$ vs $0 \%)$, and age (6\% vs $1 \%)$. Conversely, the MT/PT group more frequently assigned a critical impact to cervical ligament viability ( $39 \%$ vs 19\%), and recovery expectations ( $36 \%$ vs $25 \%$ ). At the other end of the impact scale, chiropractors more frequently assigned a small impact to cervical ligament viability ( $16 \%$ vs $7 \%$ ) and no impact to thoracic or shoulder pain (5\% vs 1\%), while the MT/PT group more frequently assigned a small impact to diagnostic imaging ( $37 \%$ vs 16\%). All differences were statistically significant at the $\mathrm{p}<0.01$ level.

\section{DISCUSSION}

A broad international survey of over 440 clinicians was conducted to capture clinical practice patterns when specifically establishing a prognosis for neck pain, as part of a broader project intended to provide guidance for developing clinical recommendations. The respondents appeared well-suited to provide opinions regarding neck pain, with two-thirds indicating that neck pain accounted for greater than $25 \%$ of their clinical caseload. The factors rated most frequently as having a large or critical impact on the clinicians' interpretation of prognosis fell into the psychological/behavioral domain, while those factors collected most frequently were within the physical domain. This may suggest that current cognitive-behavioral theories on the mechanisms of transition from acute to chronic pain [16] are gaining traction amongst clinicians. However, the survey would also suggest that clinicians are still more comfortable collecting physical indicators. An alternative, or possibly complementary, interpretation is that the frequency of collecting psychological and physical factors reported in our survey is a function of the composition of our survey sample, the majority of whom were chiropractors and physical therapists. Only a single psychologist and no psychiatrists answered the survey. The results should be interpreted in light of the characteristics of the sample.

The results suggest a mixed picture of alignment between clinical practice and current best evidence for prognosis in neck pain. Cognitive factors, such as catastrophizing and fear-avoidant behavior, were most commonly rated as having a large or critical impact on prognosis for an undesirable outcome. However, the evidence from systematic reviews on neck pain and prognosis are currently limited in supporting this viewpoint, as the evidence is generally of low quality (high risk of bias, inconsistent categorization of prognostic factors, variable follow-up intervals, inconsistent definitions of important outcomes). Systematic reviews by Kamper and colleagues [12] and Williamson and colleagues [14] found inconclusive evidence for the value of catastrophizing in predicting outcomes, while Walton and colleagues [10] found a small but significant effect through a statistical pooling procedure. The balance of literature is similar when considering fear-avoidance as a prognostic factor, with data syntheses suggesting either inconclusive $[12,14]$ or limited evidence of effect [17]. Conversely, neck pain intensity at inception is one of the few prognostic factors consistently found to have at least a moderate impact on prognosis in neck pain [10-13, 17]. Based on the results of our survey, it appears as though this general finding was not fully realized by the respondents. The moderate impact rating most commonly endorsed by respondents is accurate in terms of how much influence the factor exerts on outcomes. However, the ranking of this factor below many other factors where the evidence is weaker and the effects smaller suggest that clincians are not aware of either the strength of the evidence or absolute effects sizes when it comes to prognostic variables.

Arguably the second most consistent prognostic factor to be reported in the published literature is the moderate effect offered by baseline self-reported disability scores in the acute stage of injury [12, 13]. While only $37 \%$ of respondents indicated that disability scales had a large or critical impact, much lower than many factors lacking the same level of evidential support, the modal response of 'moderate impact' was once again consistent with the effect sizes reported in the literature in the area. Only half of the respondents reported routinely collecting baseline disability scores for the purposes of establishing a prognosis. This suggests that further knowledge translation initiatives to influence clinicians use of disability scores in prognosis establishment is warranted.

In cases of traumatic neck pain (i.e., whiplash), most syntheses in the area have yet to find convincing evidence that parameters of the accident itself are associated with clinical outcomes (e.g., direction of impact, awareness of the collision, speed of the collision, use of a head rest). More commonly, the state of the literature provides consistent evidence that accident parameters have no effect on outcomes [10-12]. Despite these findings, $70 \%$ of our respondents indicated that accident parameters had a large or critical impact on establishing a prognosis in their practice. Given that this is survey data we are not able to define what specific accident parameters were being considered; nor how they were calibrated in the prognosis. However, clinicians who put substantive weight on accident factors when making a prognosis may be misinformed.

At $97 \%$ endorsement, almost all respondents indicated that they collect active range of motion when establishing a prognosis in neck pain. Other physical factors frequently collected and endorsed as important were weakness in the upper extremities, sensory or dermatomal abnormalities, and viability of the cervical ligaments. We suspect that the collection of mobility and radicular signs are a function of the whiplash-associated disorder (WAD) grading system as proposed by the Quebec Task Force [18]. In that classification system, patients with WAD are graded on a scale from 0 to 4 , where grade 2 (restricted mobility) and 3 (radicular signs) are the most common in rehabilitation settings [18]. While some evidence exists to suggest that higher grades are associated with a worse prognosis [10, 17], other systematic reviews have been inconclusive [11-13]. More recently, primary evidence from Kasch and colleagues $[19,20]$ has provided greater support for the prognostic 
value of cervical range of motion, and may also be stimulating this practice.

The relatively high frequency with which cervical ligament viability was endorsed as being an important prognostic factor (54\% of respondents) is interesting in light of the fact that we are unaware of any prospective research that has evaluated this specific factor. This practice may be stimulated by findings from Kaale and colleagues [21] who have provided cross-sectional evidence that the magnitude of cervical ligament damage is related to self-reported disability, but this is purely speculative.

When responses were collapsed across both large and critical impact categories, $84 \%$ of respondents indicated that expectations for recovery had a strong effect on establishing a prognosis, the highest frequency of any factor. While synthesized evidence from systematic reviews or metaanalyses have yet to be published, the effect of recovery expectations on subsequent outcomes has seen increasing support. Using large population-based databases, Holm and colleagues [22] and Ozegovic and colleagues [23] have provided preliminary evidence that negative expectations for recovery in fact predict recovery from neck pain in the midto long-term. An interesting follow-up question for our respondents would have been to capture their methods for measuring both expectations and recovery, as such operationalizations are often inconsistent [24] and are an interesting area for future study.

The frequency with which the treatment-related factors of 'likelihood of compliance with treatment' and 'ability to attend treatment' were endorsed as important prognostic factors $(82 \%$ and $66 \%$, respectively) suggests that respondents see treatment as important in facilitating recovery from neck pain. In terms of prognostic research specifically, the type, mode or magnitude of treatment received has yet to be reported to a level that would permit reasonable data synthesis. Results from treatment-based reviews are mixed in terms of the value of specific treatment protocols on recovery from neck pain. Teasell and colleagues [25] have reported that immobilization in a collar appears to retard recovery while exercise alone or combined with manual therapy appear to provide benefit, the latter findings also supported by the Cochrane collaboration [26]. An economic decision analysis by Van der Velde found generally equal effectiveness across drugs, exercise, mobilization or manipulation [27]. More detailed protocols have yet to be firmly established, so the prognostic importance placed on these variables by our respondents is interesting but difficult to interpret.

The comparisons conducted between the MT/PT and chiropractor groups provide some insight into the differences in prognostic approaches between the groups, few of which are surprising. Chiropractors, who have historically been able to collect and interpret medical images, reported greater frequency and importance of imaging findings compared to the MT/PT clinical group who generally are not able to order such investigations. Conversely, the MT/PT group, arguably more focused on soft tissue-related dysfunction, more frequently collected and assigned importance to the expectations of recovery in their patients and the viability of cervical ligaments. More refined interpretation of these differences is not warranted given the design of this study, other than to note that the results appear to generally support the anticipated practice patterns of these rehabilitation professions. Further, since neither imaging nor ligament testing has strong evidence for being prognostic, these differences are unlikely to lead to any difference between these disciplines in terms of prognostic accuracy.

Survey research, especially when conducted internationally, has inherent limitations and cautions which must be addressed. We do not know how many people accessed the survey but then decided against participating, leaving an incomplete picture of the response rate. It is entirely possible that those who engaged in the survey are different from the rest of the population of practicing clinicians, and as such the results are not an accurate depiction of routine clinical practice. Further, despite a rigorous process of item generation, pilot testing, and revision, we cannot be confident that the items or response options were interpreted in the same way by all respondents. The survey was only offered in English, and as such those for whom English was not their first language may have found that not all items or responses translated easily. The sample was primarily from North America (64\%) and from non-medical, rehabilitation fields such as physical therapy, chiropractic, manual therapy or massage therapy $(90 \%$ combined). Since these groups are common treatment providers, the data on these groups is highly relevant. However, findings should not be generalized beyond these professional groups. In particular, family physicians, physiatrists and orthopedic surgeons who treat neck pain were under-represented. Further mental health professionals may not see themselves as specifically treating neck pain, but are often involved with chronic pain or mental health conditions that are secondary to it. Sampling from this group was particularly challenging and may not adequately reflect the involvement of these professions in this area. Considering that the majority of cases of uncomplicated or mechanical neck pain are treated by rehabilitation professionals our findings can be considered somewhat representative of standard practice but not exhaustive.

It is impossible for us to determine whether respondents fully grasped the purpose of this particular survey, and that was to indicate which factors were routinely captured for the specific purpose of establishing a prognosis in neck pain of any cause or duration. It is possible that some factors were reported as frequently collected due to their roles as routine components of clinical assessment (i.e., age and gender), but not specifically for their value as prognostic indicators. As an illustration, while age and gender were endorsed as being routinely collected by over $90 \%$ of respondents, their modal levels of importance for establishing a prognosis was small and moderate, respectively. The high frequency rating for these factors may have been more an indication of ease rather than usefulness.

Survey research must be interpreted within the boundaries of the sample and the intent of the items. It is difficult to draw firm conclusions from a cross-sectional 'snapshot' of practice. The intention was to provide a general sense of practice patterns at one time, with a secondary goal to provide a cursory comparison between reported practice and current evidence. We believe we have succeeded in that goal. The comparisons between these two sources of 
knowledge have provided important insights into the gap between research and practice. The fact that any factor received a rating of 'large' impact, let alone critical, is not in keeping with the current state of literature. While it may be possible that the settings within which our respondents practice are considerably different from those that have been used to establish the evidence base in these areas, a more likely interpretation is that the results of published systematic reviews and other knowledge translation initiatives have yet to influence clinical practice patterns. If this is the case, establishment of prognosis in neck pain may be often misguided. However, an important alternative viewpoint to interpreting any of these results is that clinicians are in fact aware of clinically important prognostic factors for which empirical evidence has yet to accumulate. Regardless of whether evidence has yet to adequately inform practice, or practice has yet to adequately inform evidence, our results suggest that clinicians and researchers both have potentially valuable knowledge to share with each other.

\section{CONCLUSIONS}

A gap appears to exist between best evidence and clinical practice in the field of prognosis for neck pain. Our respondents correctly identified that pain intensity and selfreported disability scales have a moderate impact on outcome, but reported relatively low rates of collecting this information. Other factors were perceived as having a high impact on outcomes when evidence for this is lacking. In particular, this was true for fear avoidance and passive coping strategies. However, reasons for optimism are also present. The generally high importance assigned to the psychological and behavioral factors suggests a growing appreciation for a more holistic approach to establishing a prognosis beyond purely physical signs. This is consistent with the current state of evidence that suggests that prognosis requires knowledge of factors across biopsychosocial domains. Clinicians in traditionally biomedical fields are encouraged to look outside of their respective fields to gain a better appreciation for the full nature of injury, health and predicting recovery.

\section{CONFLICT OF INTEREST}

The authors confirm that this article content has no conflict of interest.

\section{ACKNOWLEDGEMENTS}

ICON is a multi-disciplinary collaborative group that includes scientist-authors (listed below) and support staff (Margaret Lomotan) that conduct knowledge synthesis and translation aimed at reducing the burden of neck pain.

The ICON authors provided direction of the project; input into the interview questions and review of the findings/manuscript and includes (in alphabetical order): Gert Bronfort, Norm Buckley, Lisa Carlesso, Linda Carroll, Pierre Côté, Jeanette Ezzo, Paulo Ferreira, Tim Flynn, Charlie Goldsmith, Anita Gross, Ted Haines, Jan Hartvigsen, Wayne Hing, Gwendolyn Jull, Faith Kaplan, Ron Kaplan, Helge Kasch, Justin Kenardy, Per Kjær, Janet Lowcock, Joy MacDermid, Jordan Miller, Margareta Nordin, Paul Peloso, Jan Pool, Duncan Reid, Sidney Rubinstein, Lina Santaguida, Anne Söderlund, Natalie Spearing, Michele Sterling, Grace
Szeto, Robert Teasell, Arianne Verhagen, David M. Walton, Marc White.

This work was supported by Canadian Institutes of Health Research (CIHR) grant FRN: KRS-102084

\section{REFERENCES}

[1] Dworkin RH, Turk DC, Peirce-Sandner S, et al. Considerations for improving assay sensitivity in chronic pain clinical trials: IMMPACT recommendations. Pain 2012; 153(6): 1148-58.

[2] Jull G, Soderlund A, Stemper B, et al. Towards optimal early management after whiplash injury to lessen the rate of transition to chronicity: Discussion paper 5. Spine (Phila Pa 1976) 2011; 36 (25 Suppl): S335-42.

[3] Jull GA, Sterling M, Curatolo M, Carroll L, Hodges P. Toward lessening the rate of transition of acute whiplash to a chronic disorder. Spine (Phila Pa 1976) 2011; 36(25 Suppl): S173-4.

[4] Sterling M. Does knowledge of predictors of recovery and nonrecovery assist outcomes after whiplash injury? Spine (Phila $\mathrm{Pa}$ 1976) 2011; 36(25 Suppl): S257-62.

[5] U.S. Department of Health and Human Services. Factsheet: Understanding prognosis and cancer statistics: Questions and Answers [FactSheet 03/07/2008] 2008.

[6] Santaguida PL, Hawker GA, Hudak PL, et al. Patient characteristics affecting the prognosis of total hip and knee joint arthroplasty: a systematic review. Can J Surg 2008; 51(6): 428-36.

[7] Croft PR, Lewis M, Papageorgiou AC, et al. Risk factors for neck pain: a longitudinal study in the general population. Pain 2001; 93(3): 317-25.

[8] Cote P, Kristman V, Vidmar M, et al. The prevalence and incidence of work absenteeism involving neck pain: a cohort of Ontario lost-time claimants. Spine (Phila Pa 1976) 2008; 33(4 Suppl): S192-8.

[9] Cote P, Hogg-Johnson S, Cassidy JD, Carroll L, Frank JW, Bombardier C. Initial patterns of clinical care and recovery from whiplash injuries: a population-based cohort study. Arch Intern Med 2005; 165(19): 2257-63.

[10] Walton DM, Pretty J, MacDermid JC, Teasell RW. Risk factors for persistent problems following whiplash injury: results of a systematic review and meta-analysis. J Orthop Sports Phys Ther 2009; 39(5): 334-50.

[11] Scholten-Peeters GG, Verhagen AP, Bekkering GE, et al. Prognostic factors of whiplash-associated disorders: a systematic review of prospective cohort studies. Pain 2003; 104(1-2): 303-22.

[12] Kamper SJ, Rebbeck TJ, Maher CG, McAuley JH, Sterling M. Course and prognostic factors of whiplash: A systematic review and meta-analysis. Pain 2008; 138(3): 617-29.

[13] Williams M, Williamson E, Gates S, Lamb S, Cooke M. A systematic literature review of physical prognostic factors for the development of Late Whiplash Syndrome. Spine 2007; 32(25): E764-80.

[14] Williamson E, Williams M, Gates S, Lamb SE. A systematic literature review of psychological factors and the development of late whiplash syndrome. Pain 2008; 135(1-2): 20-30.

[15] Cote P, Cassidy JD, Carroll L, Frank JW, Bombardier C. A systematic review of the prognosis of acute whiplash and a new conceptual framework to synthesize the literature. Spine 2001; 26(19): E445-58.

[16] Leeuw M, Goossens ME, Linton SJ, Crombez G, Boersma K, Vlaeyen JW. The fear-avoidance model of musculoskeletal pain: current state of scientific evidence. J Behav Med 2007; 30(1): 7794.

[17] Carroll LJ, Holm LW, Hogg-Johnson S, et al. Course and prognostic factors for neck pain in whiplash-associated disorders (WAD): results of the Bone and Joint Decade 2000-2010 Task Force on Neck Pain and Its Associated Disorders. Spine 2008; 33 (4 Suppl): S83-92.

[18] Spitzer WO, Skovron ML, Salmi LR, et al. Scientific monograph of the Quebec Task Force on Whiplash-Associated Disorders: redefining "whiplash" and its management. Spine 1995; 20(8 Suppl): 1S-73S.

[19] Kasch H, Qerama E, Kongsted A, Bach FW, Bendix T, Jensen TS. The risk assessment score in acute whiplash injury predicts outcome and reflects biopsychosocial factors. Spine (Phila Pa 1976) 2011; 36(25 Suppl): S263-7. 
[20] Kasch H, Qerama E, Kongsted A, Bendix T, Jensen TS, Bach FW. Clinical assessment of prognostic factors for long-term pain and handicap after whiplash injury: a 1-year prospective study. Eur J Neurol 2008 ; 15(11): 1222- 30.

[21] Kaale BR, Krakenes J, Albrektsen G, Wester K. Whiplashassociated disorders impairment rating: neck disability index score according to severity of MRI findings of ligaments and membranes in the upper cervical spine. J Neurotrauma 2005; 22(4): 466- 75.

[22] Holm LW, Carroll LJ, Cassidy JD, Skillgate E, Ahlbom A. Expectations for recovery important in the prognosis of whiplash injuries. PLoS Med 2008 ; 5(5): e105.

[23] Ozegovic D, Carroll LJ, David Cassidy J. Does expecting mean achieving? The association between expecting to return to work and recovery in whiplash associated disorders: a population-based prospective cohort study. Eur Spine J 2009 ; 18(6): 893- 9.
[24] Walton D. A review of the definitions of recovery used in prognostic studies on whiplash using an ICF framework. Disabil Rehabil 2009; 31(12): 943- 57.

[25] Teasell RW, McClure JA, Walton D, et al. A research synthesis of therapeutic interventions for whiplash-associated disorder (WAD): part 2 - interventions for acute WAD. Pain Res Manag 2010; 15(5): 295-304.

[26] Gross AR, Hoving JL, Haines TA, et al. A Cochrane review of manipulation and mobilization for mechanical neck disorders. Spine 2004; 29(14): 1541-8.

[27] van der Velde G, Hogg-Johnson S, Bayoumi AM, et al. Identifying the best treatment among common nonsurgical neck pain treatments: a decision analysis. J Manipulative Physiol Ther 2009; 32(2 Suppl): S209-18. 